Олег Володимирович Павловський (доктор військових наук, с.н.с) ${ }^{1}$

Валентин Юрійович Мазур (доктор військових наук, доцент) ${ }^{2}$

Віталій Францович Таргонський ${ }^{1}$

${ }^{1}$ Центральний науково-дослідний інститут Збройних Сил Украйни, Киӥв, Украӥна

${ }^{2}$ Національна академія Державної прикордонної служби Украйни імені Богдана Хмельницького, м. Хмельницький, Украӥна

\title{
МЕТОДИЧНИЙ ПІДХІД ЩОДО ОБҐРУНТУВАННЯ СКЛАДУ РЕМОНТНИХ ПІДРОЗДІЛІВ ДЛЯ ВІДНОВЛЕННЯ ТЕХНІКИ ТИЛУ ОПЕРАТИВНОГО УГРУПОВАННЯ ВІЙСЬК
}

Аналіз війн та збройних конфліктів останніх років та виконання завдань військовими частинами (підрозділами) в операції Об’еднаних сил (антитерористичній операції) підтверджує, щзо успіх виконання завдань механізованими, танковими, десантно-итурмовими та іншими військовими частинами (підрозділами) буде залежати від ефективності функиіонування системи забезпечення військ (сил).

Знаходження військових частин (підрозділів), які ведуть бойові дії, у постійному боєздатному стані буде залежати від ефективності функціонування системи забезпечення, тобто, як будуть підрозділи логістики здійснювати підвезення матеріальних засобів, паливно-мастильних матеріалів, відновлювати пошкоджені зразки озброєнні та військової техніки, тощэо. При изьому, ефективність їх функиіонування повною мірою буде залежати від своєчасного і якісного відновлення техніки тилу, яка отримала бойові або експлуатаційні пошкодження, ремонтно-відновлювальними військовими частинами ( підрозділами).

Тому у статті запропоновано методичний підхід щзодо обтрунтування складу ремонтних підрозділів для відновлення техніки тилу оперативного угруповання військ, який грунтується на вирішенні оптимізаційної задачі цілочисельного нелінійного програмування з мінімізації затрат, призначених для ремонту та утримання резервних зразків техніки тилу.

Ключові слова: ремонт; відновлення; резерв; техніка тилу.

\section{Вступ}

Аналіз застосування підрозділів та військових частин сил логістики на території Донецької та Луганської областей дозволяє стверджувати, що одним із основних чинників, які впливають на успіх у забезпеченні механізованих (танкових) військових частин це $\epsilon$ наявність в строю працездатних зразків техніки тилу (ТТл). При цьому, одним із основних джерел надходження в підрозділи (військові частини) працездатних зразків ТТг в ході ведення бойових дій $\epsilon$ повернення їх iз стаціонарних та рухомих ремонтно-відновлювальних військових частин (підрозділів) після виконання заходів 3 відновлення.

Але, як показав досвід виконання завдань в операції Об'єднаних сил (АТО) - сили логістики, стикнулись 3 певними проблемами, які були викликані тим, що ремонтно-відновлювальні підрозділи (військові частини) були неспроможні охопити увесь ремонтний фонд, який потребував відновлення.

Постановка проблеми. Під час проведення операцій (бойових дій) усунення втрат (ТТл) здійснюється, зазвичай, двома способами. Перший спосіб грунтується на постачанні відремонтованих зразків ТТл, що отримали експлуатаційні та бойові пошкодження, другий - на подачі ТТл з резерву, який утримується в центрах забезпечення (базах, складах).

Отже, під час обгрунтування раціонального складу сил і засобів ремонту ТТл головну увагу слід приділяти визначенню такого складу ремонтних органів (РО), зокрема, кількості ремонтних відділень (ремвід) та ремонтних комплектів (РК) у них, а також кількості резервних зразків ТТл, які б забезпечували укомплектування ними військ протягом операції на рівні, не нижчому від заданого рівня укомплектованості $\mathrm{K}_{\mathrm{TTл}}^{\text {(вим) }}$

Аналіз останніх досліджень і публікацій. Аналіз наукових праць, присвячених предметній галузі, яка досліджується, свідчить про те, що проблематика обгрунтування складу сил і засобів системи забезпечення військ озброєнням та військовою технікою вже була об'єктом наукового пошуку $[1,2]$. Для вирішення подібних питань пропонувалися різноманітні підходи, сутність яких, головним чином, зводилась до знаходження такої кількості зазначених сил і засобів, яка б 
дозволяла із заданою ймовірністю виконувати покладені на них завдання. Зокрема в роботі [3] запропонований метод прогнозування величини втрат озброєння та військової техніки, які виникають у військах (сила) під час ведення бойових дій (операціі). У роботі [4] наводиться методика визначення обсягу обмінного фонду агрегатів для ремонту ОВТ. Запропонований алгоритм вирішення задачі щодо зменшення логістичних витрат, який базується на розгляді системи обмінного фонду агрегатів. Так у роботі [5] пропонується структура ієрархії задач до груп поточного ремонту ОВТ в місцях їх дислокації, яка заснована на оптимізації складу і стратегії використання цих груп, а у роботі [6] розглянуто підхід до визначення втрат автомобільної техніки під час ведення територіальної оборони. В роботі [7] запропоновано методичний підхід до оцінювання економічної ефективності ремонту зразків ОВТ, який враховує фінансово-економічні витрати на ремонт ОВТ в стаціонарних умовах та у рухомих ремонтно-відновлювальних військових частинах (підрозділах). В роботі [8] визначено, що ефективне управління інформаційними потоками у системі логістики буде залежати від ступені ii автоматизації. Запропоновано складові системи управління, на основі яких буде прогнозуватись потреба військових частин (підрозділів) у матеріально-технічних засобах, визначатись на який час їх необхідно подати, у якому об'ємі та оптимальний маршрут їх підвезення, а в роботі [9] для вирішення завдання щодо своєчасного забезпечення військових частин (підрозділів) матеріальними засобами (М3) запропоновано метод оптимізації матеріальних потоків. В літературних джерелах [10] запропоновано методику оцінювання відновлюваності ОВТ, згідно якої основним оціночним параметром відновлюваності зразків ОВТ може служити середній час простою ОВТ в ремонті., а у роботі [11] запропонована методика оцінювання ефективності функціонування системи відновлення. Суть якої полягає в отриманні відомостей про надійність відновлення ОВТ за номенклатурою в кожній ланці структури системи відновлення, кількості відновлених зразків ОВТ на кожному рівні ієрархії, кількості неохоплених ремонтно-відновлювальними роботами зразків OBT в кожній ланці, кількості працездатних зразків ОВТ на кожну добу операції (бойових дій).

Головним недоліком такого підходу є те, що значення потрібної величини ймовірності виконання покладених завдань нормативно не визначене, і його вибір, як правило, залежить лише від особи, яка приймає рішення. Це зумовлює суттєву залежність отриманих результатів від суб'єктивних факторів, що не можна вважати прийнятним. Крім того, недостатньо адекватно враховувався вплив РК на результати функціонування РО.

Таким чином, методичний підхід щодо обгрунтування складу ремонтних підрозділів для відновлення техніки тилу, якій враховує найбільш вагомі недоліки існуючих методичних підходів $є$ актуальним питанням.

Мета статті. Метою статті $\epsilon$ висвітлення методичного підходу щодо обгрунтування складу ремонтних підрозділів для відновлення техніки тилу оперативного угруповання військ.

\section{Виклад основного матеріалу дослідження}

Запропонований методичний підхід складається 3 таких взаємно пов'язаних етапів (рис. 1):

підготовка вихідних даних;

визначення кількості зразків ТТл, які необхідно повернути до строю під час операції для підтримання потрібного рівня укомплектованості військ технікою тилу;

визначення потрібної кількості ремонтних відділень та ремонтних комплектів для підтримання потрібного (заданого) рівня укомплектованості військ технікою тилу.

На першому етапi визначається кількість зразків ТТл $(\delta N)$, які необхідно повернути до строю під час операції (за рахунок відновлення або резерву) для підтримання потрібного (заданого) рівня укомплектованості військ технікою тилу $\mathrm{K}_{\text {ТТл }}^{\text {(вим }}$.

Для виконання цього спочатку слід розрахувати:

прогнозовану кількість ТТл в строю $(N)$ за умови, якщо не проводитиметься ії ремонт та буде відсутній резерв;

потрібну кількість техніки тилу в строю $\left(N^{(\text {(вим) })}\right.$ для підтримання значення $\mathrm{K}_{\text {ТТл }}^{(\text {вим) }}$.

При цьому:

$$
\begin{gathered}
\mathrm{N}=\mathrm{N}_{0}-\Delta \mathrm{N}=\mathrm{N}_{0}-\mathrm{N}_{0} \cdot \beta=\mathrm{N}_{0} \cdot(1-\beta), \\
\beta=\beta_{0} \cdot \mathrm{K}_{\Phi} \cdot \mathrm{K}_{\text {Отв }} \cdot \mathrm{K}_{\mathrm{CC}} \cdot \mathrm{T}, \\
\mathrm{N}^{\text {(вим })}=\mathrm{N}_{0} \cdot \mathrm{K}_{\mathrm{TТл}}^{\text {вим }}
\end{gathered}
$$

де $\beta$ - прогнозовані відносні втрати ТТл протягом операції;

$\beta_{0}-$ показник норми середньодобових безповоротних втрат, що очікуються, виходу у ремонт (капітальний, середній, поточний) ОВТ, втрат i витрат інших матеріально-технічних засобів;

$K_{\Phi}-$ коефіцієнт форми застосування військ;

$\kappa_{\text {отв }}$ - коефіцієнт урахування ролі і місця військового формування в операції (бойових діях);

$K_{C C}-$ коефіцієнт урахування співвідношень сил і засобів сторін в операції (бойових діях);

$T$ - тривалість операції (діб);

$N_{0}$ - кількість зразків ТТл згідно зі штатнотабельною потребою;

$\Delta N$ - прогнозована кількість втрачених зразків ТТл протягом усієї операції (бойових дій). 


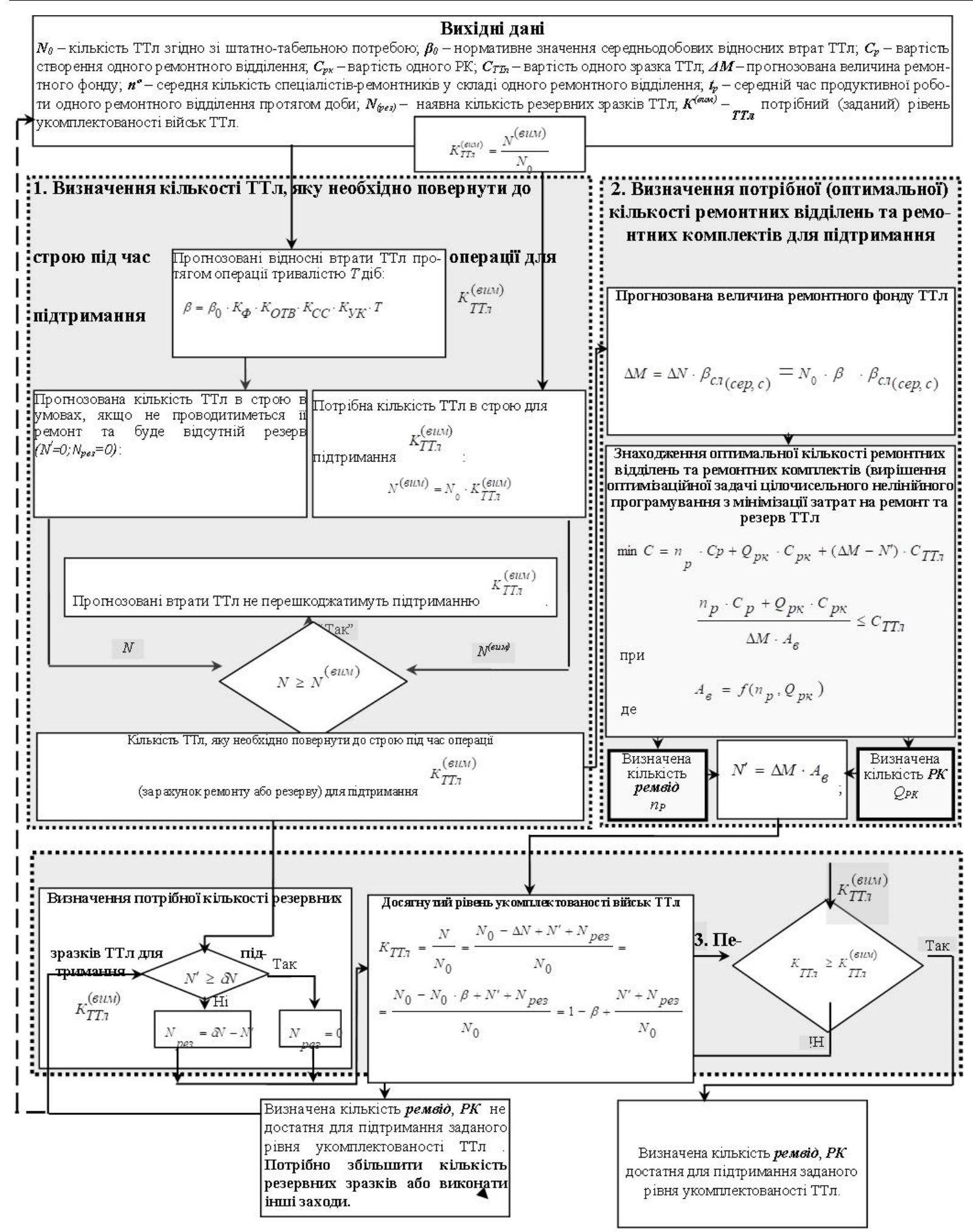

Рис. 1 Блок-схема методичного підходу щодо обгрунтування складу ремонтних підрозділів для відновлення техніки тилу оперативного угруповання військ

Після цього перевіряється виконання умови

$$
\mathrm{N} \geq \mathrm{N}^{\text {(вим })}
$$

Якщо наведена умова виконуватиметься, то це свідчить про те, що прогнозовані втрати ТТл не перешкоджатимуть підтриманню протягом операції (бойових дій) забезпеченості військ ТТл на рівні, не нижчому від $\mathrm{K}_{\text {ТТл }}^{\text {(вим }}$. Якщо ж не виконуватиметься, то це свідчитиме про те, що прогнозовані втрати ТТл перешкоджатимуть підтриманню протягом операції (бойових дій) забезпеченості військ технікою тилу на рівні, не нижчому від $\mathrm{K}_{\text {ТТл }}^{\text {(вим) }}$. У такому разі повернення певної кількості зразків ТТл $(\delta N)$ до строю під час операції необхідно здійснювати за 
рахунок ремонту або резерву. Потрібне значення $\delta N$ являтиме собою різницю $N^{\left(\text {(uus) }^{2}\right.}$ та $N$

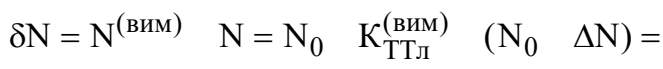

$$
\begin{aligned}
& =\mathrm{N}_{0} \quad \mathrm{~K}_{\text {ТТл }}^{\text {(вим })}\left(\begin{array}{llll}
\mathrm{N}_{0} & \mathrm{~N}_{0} & \beta
\end{array}\right)= \\
& =\mathrm{N}_{0} \quad\left(\beta+\mathrm{K}_{\text {ТТл }}^{\text {(вим })} \quad 1\right)
\end{aligned}
$$

На другому emani визначається потрібна кількість ремонтних відділень та ремонтних комплектів для підтримання значення $\mathrm{K}_{\mathrm{TTл}}^{\text {(вим) }}$.

Для цього спочатку розраховується прогнозована величина загального ремонтного фонду ТТл $(\Delta M)$ за таким виразом

$$
\Delta \mathrm{M}=\Delta \mathrm{N} \quad \beta_{\text {сл(сер, с) }}=\mathrm{N}_{0} \quad \beta \quad \beta_{\text {сл(сер, с) })},
$$

де $\beta$ (сл, сер, с) - відносні втрати зразків ТТл, які отримали пошкодження певного ступеня: $c л-$ слабкі, сер - середні, $c$ - сильні.

Величина $\beta$ сл (cеp, с) визначається залежно від складності ремонту, який виконується РО ТТл того чи іншого рівня підпорядкованості військ.

Наступна операція - знаходження потрібної кількості ремонтних відділень та ремонтних комплектів шляхом вирішення оптимізаційної задачі цілочисельного нелінійного програмування 3 мінімізації затрат на ремонт та резерв ТТл, де:

цільова функція

$$
\begin{aligned}
& \min \mathrm{C}=\mathrm{n}_{\mathrm{p}} \quad \mathrm{C}_{\mathrm{p}}+\mathrm{Q}_{\mathrm{p \kappa}} \quad \mathrm{C}_{\mathrm{p \kappa}}+ \\
& +\left(\begin{array}{lll}
\Delta \mathrm{M} & \mathrm{N}^{\prime}
\end{array}\right) \quad \mathrm{C}_{\mathrm{TTл}}=\mathrm{n}_{\mathrm{p}} \quad \mathrm{C}_{\mathrm{p \kappa}}+\mathrm{Q}_{\mathrm{p \kappa}} \quad \mathrm{C}_{\mathrm{p \kappa}}+
\end{aligned}
$$

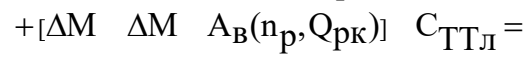

$$
\begin{aligned}
& =\mathrm{n}_{\mathrm{p}} \quad \mathrm{C}_{\mathrm{p \kappa}}+\mathrm{Q}_{\mathrm{p \kappa}} \quad \mathrm{C}_{\mathrm{p \kappa}}+ \\
& +\Delta \mathrm{M} \quad \mathrm{C}_{\mathrm{TT}}\left[1 \quad \mathrm{~A}_{\mathrm{B}}\left(\mathrm{n}_{\mathrm{p}}, \mathrm{Q}_{\mathrm{p \kappa}}\right)\right] \\
& \text { обмеження } \\
& \frac{\mathrm{n}_{\mathrm{p}} \cdot \mathrm{C}_{\mathrm{p}}+\mathrm{Q}_{\mathrm{p \kappa}} \cdot \mathrm{C}_{\mathrm{p \kappa}}}{\Delta \mathrm{M} \cdot \mathrm{A}_{\mathrm{B}}} \leq \mathrm{C}_{\text {ТТл }}
\end{aligned}
$$

змінні

$$
\mathrm{n}_{\mathrm{p}}=0,1,2, \ldots ; \mathrm{Q}_{\mathrm{p \kappa}}=0,1,2, \ldots,
$$

де $\mathrm{n}_{\mathrm{P}}$ - кількість каналів обслуговування (ремонтних відділень) у РО;

$\mathrm{C}_{\mathrm{p}}$ - вартість створення одного ремвід;

$\mathrm{Q}_{\mathrm{p \kappa}}-$ кількість РК;

$\mathrm{C}_{\text {рк }}$ - вартість одного РК;

$\mathrm{N}^{\prime}$ - кількість відновлених зразків ТТл;

$\mathrm{C}_{\mathrm{TTл}}$ - вартість одного зразка ТТл;

$\mathrm{A}_{\mathrm{B}}$ - ймовірність своєчасного відновлення ТТл.

Для визначеної таким чином оптимальної кількості ремвід та РК розраховується прогнозована кількість відремонтованих 3 їхнім використанням зразків ТТл $\left(N^{\prime}\right)$ за такими виразами

$$
\begin{aligned}
& \mathrm{N}^{\prime}=\Delta \mathrm{M} \quad \mathrm{A}_{\mathrm{B}}=\Delta \mathrm{M} \quad \mathrm{A}_{\mathrm{p}}= \\
& =\mathrm{N}_{0} \quad \beta \quad \beta_{\text {сл(сер, }, \mathrm{c})} \quad \mathrm{A}_{\mathrm{p}}
\end{aligned}
$$

де $\mathrm{A}_{\mathrm{P}}-$ ймовірність своєчасного ремонту пошкоджених зразків ТТл;

$\varphi$ - функція, яка враховує наявність певної кількості РК, а також можливість проведення ремонту в умовах, коли РК відсутні і ремонт здійснюють, використовуючи як джерело запасних частин пошкоджені зразки ТТл, що належать до безповоротних втрат.

Величина $\mathrm{A}_{\mathrm{p}}$ може бути визначена за допомогою моделей функціонування ремонтних органів, які основані на представлені ремонту ТТл у вигляді марковських багатоканальних однорідних СМО [12].

Величина $\varphi$ може бути розрахована за допомогою виразів:

$$
\varphi=0,3+0,7 \cdot \frac{\mathrm{Q}_{\mathrm{p \kappa}} \cdot \mathrm{N}_{\mathrm{p} 1},}{\mathrm{~N}^{\prime}},
$$

де $\mathrm{N}_{\mathrm{p} 1}$ - кількість зразків ТТл, які можливо відновити за рахунок 1-го ремонтного комплекту.

На mpemboмy emani визначається досягнутий рівень $\left(\mathrm{K}_{\text {ТТл }}\right)$ укомплектованості військ ТТл за умови наявності визначеної на другому етапі кількості ремвід та РК. У разі, якщо досягнення величини К буде не менше, ніж потрібний (заданий) рівень укомплектованості військ ТТл, це свідчитиме про те, що визначена кількість ремвід, РК та резервних зразків ТТл достатня для підтримання заданого рівня укомплектованості ТТл, якщо ж ні, то це означатиме що визначена кількість ремвід, РК та резервних зразків ТТл недостатня для підтримання заданого рівня укомплектованості ТТл і $є$ потреба у збільшені кількості резервних зразків або проведенні інших заходів.

Потрібна кількість резервних зразків ТТл $\left(N_{\text {рез }}\right)$ становитиме

$$
\begin{aligned}
& \mathrm{N}_{\text {peз }}=\delta \mathrm{N} \quad \mathrm{N}^{\prime}=\mathrm{N}_{0} \quad\left(\beta+\mathrm{K}_{\text {ТТл }}^{\text {(вим })} 1\right) \\
& -\mathrm{N}_{0} \quad \beta \quad \mathrm{A}_{\mathrm{p}} \quad=\mathrm{N}_{0} \quad\left(\beta+\mathrm{K}_{\text {ТТл }}^{\text {(вим }} \quad 1 \quad \beta \quad \mathrm{A}_{\mathrm{p}} \quad\right)= \\
& \left.=\mathrm{N}_{0} \quad\left[\begin{array}{llll}
\beta & (1 & \mathrm{A}_{\mathrm{p}} & )
\end{array}\right)+\mathrm{K}_{\text {ТТл }}^{\text {(вим }} \quad 1\right]
\end{aligned}
$$

\section{Висновки й перспективи подальших досліджень}

Запропонований методичний підхід дозволяє обгрунтувати склад сил і засобів ремонту ТТл оперативного угруповання військ в оборонній операції, зокрема, розраховувати кількість ремвід та РК. Крім того, методичний підхід дає можливість розраховувати кількість зразків ТТл, які потрібно утримувати в резерві.

Новизною методичного підходу $є$ те, що він грунтується на вирішенні оптимізаційної задачі цілочисельного нелінійного програмування 3 мінімізації затрат на ремонт та резерв ТТл.

Перспективами подальших досліджень може бути формування аналітичної моделі функціонування ремонтних органів техніки тилу, яка буде сприяти адекватному моделювання процесів, що відбуваються під час ремонту ТТл. 
1. Шуєнкін В. О. Теоретичні основи матеріальнотехнічного забезпечення військ (сил): навч. посіб. / В. О. Шуєнкін, І. С. Ішутін та ін. - Київ: ЦНДІ ЗС України, 2006. Ч. 1. 326 с. 2. Закусило П. С. Методика обгрунтування вимог до системи комплексного ремонту бронетанкового озброєння і техніки армійського корпусу в оборонній операції: дис. канд. військ. наук: 20.01 .05 «Будівництво Збройних Сил» / П. С. Закусило. Київ, 2002. 175 с. 3. Павловський О.В. Прогнозування величини втрат озброєння та військової техніки під час операцій (бойових дій). Системи озброєння $і$ військова техніка, 2015, № 4(44), с. 116-118. 4. Морозов, О.О. Методика визначення обсягу обмінного фонду агрегатів для ремонту озброєння і військової техніки. Військовотехнічний збірник, 2017, №16, с. 55-59. 5. Морозов, O.O. Методика формування вимог до груп поточного ремонту озброєння і військової техніки. Системи озброєння і військова техніка, 2016, № 1(45) с. 51-55. 6. Шостак, В.Г. К задаче определения потерь автомобильной техники территориальных войск. Вестник военной академии республики Беларусь. 2013, №2(39). - C.68-72 7. V. Dachkovskyi Methodical approach to evaluation of economic efficiency of repairing the weapons and military equipment. Journal of Scientific Papers VUZF review. - 2020. - Vol. 5, No 1, p. 22-30.
DOI: https://doi.org/10.38188/2534-9228.20.1.03

8. Гаврилюк І.Ю. Мацько, О.Й. Дачковський, В.О. Концептуальні основи управління потоками в системі логістичного забезпечення Збройних Сил України. Сучасні інформаційні технології у сфері безпеки та оборони, - 2019. - № 1(34) C. 37 - 44. DOI:10.33099/2311-7249/2019-34-1-37-44.

9. Dachkovskyi, V.O. The method of the optimization of material flows for functioning of the recovery system. Social development \& Security. - 2020. - №10(2), 27-34. DOI: https://doi.org/10.33445/sds.2020.10.2.4

10. Дачковський, В.О. Радченко, Л.М. Методика оцінювання відновлюваності озброєння та військової техніки. Сучасні інформаційні технологї у сфері безпеки та оборони, - 2019. - № 3(36) С. 89-96. DOI:10.33099/2311-7249/2019-36-3-89-96

11. Дачковський, В.О. Коцюруба, B.I. Методика оцінювання ефективності функціонування системи відновлення озброєння та військової техніки. Сучасні інформачійні технології у сфері безпеки та оборони. 2020. - № 1(37) C. 5-14. DOI:10.33099/2311-7249/202037-1-5-14 12. Шуєнкін В. О., Донченко В. С. Прикладные модели теории массового обслуживания / Київ: НМК ВО «Учебно-методический кабинет высшего образования», 1992.398 с.

\title{
МЕТОДИЧЕСКИЙ ПОДХОД К ОБОСНОВАНИЮ СОСТАВА РЕМОНТНЫХ ПОДРАЗДЕЛЕНИЙ ДЛЯ ВОССТАНОВЛЕНИЯ ТЕХНИКИ ТЫЛА ОПЕРАТИВНОЙ ГРУППИРОВКИ ВОЙСК
}

\author{
Олег Владимирович Павловский (доктор военных наук, с.н.с) ${ }^{1}$ \\ Валентин Юревич Мазур (доктор военных наук, доцент) ${ }^{2}$
} Виталий Францович Таргонский

\footnotetext{
${ }^{1}$ Центральный научно-исследовательский институт Вооружённых Сил Украины, Киев, Украина

${ }^{2}$ Национальная академия Государственной пограничной службы Украины имени Богдана Хмельницкого, Хмельницкий, Украина
}

Анализ войн и вооруженных конфликтов последних лет и выполнения задач воинскими частями (подразделениями) в операции Объединенных сил (антитеррористической операции) подтверждает, что успех выполнения задач механизированными, танковыми, десантно-штурмовыми и другими воинскими частями (подразделениями) будет зависеть от эффективности функиионирования системь обеспечения войск (сил).

Нахождение военных частей (подразделений), которые ведут боевые действия, в постоянном боеспособном состоянии будет зависеть от эффективности функционирования системь обеспечения, то есть, как будут подразделения логистики осуществлять подвоз материальных средств, горючесмазочные материалы, восстанавливать поврежденные образиы вооружения и военной техники и тому подобное. При этом, эффективность их функиионирования в полной мере будет зависеть от своевременного и качественного восстановления техники тыла, которая получила боевые или эксплуатационные повреждения, ремонтно-восстановительными войсковыми частями (подразделениями).

Поэтому в статье предложен методический подход к обоснованию состава ремонтных подразделений для восстановления техники тыла оперативной группировки войск, основанный на решении оптимизационной задачи целочисленного нелинейного программирования по минимизации затрат, предназначенных для ремонта и содержания резервных образиов техники тыла.

Ключевые слова: ремонт; восстановление; резерв; техника тыла.

\section{METHODICAL APPROACH TO SUBSTANTIATION OF THE COMPOSITION OF REPAIR DIVISIONS FOR RESTORATION OF BODY TECHNIQUE OF THE OPERATIONAL GROUP OF VISA}

\author{
Oleh Pavlovskyi (Doctor of Military Sciences, Senior Research Fellow) ${ }^{1}$ \\ Valentyn Mazur (Doctor of Military Sciences, Associate Professor) ${ }^{2}$
}

Vitalii Tarhonskyi ${ }^{1}$ 


\section{${ }^{1}$ Central research institute of Armed Force of Ukraine \\ ${ }^{2}$ National Academy of State Border Guard Service of Ukraine name after Bohdan Khmelnitsky}

Analysis of wars and armed conflicts in recent years and the implementation of tasks by military units (units) in the Joint Forces operation (anti-terrorist operation) confirms that the success of tasks of mechanized, tank, assault and other military units (units) will depend on the effectiveness of troops (forces) support systems.

The location of military units (units) conducting combat operations in a constant state of combat will depend on the efficiency of the support system, ie how the logistics units will deliver materials, fuel and lubricants, restore damaged samples of weapons and military equipment, etc. At the same time, the effectiveness of their operation will fully depend on the timely and high-quality restoration of rear equipment, which received combat or operational damage, repair and recovery units (units).

Therefore, the article proposes a methodological approach to substantiate the composition of repair units for the restoration of rear equipment of the operational group of troops, which is based on solving the optimization problem of integer nonlinear programming to minimize costs for repair and maintenance of backup samples of rear equipment.

Keywords: repair; restoration; reserve; rear equipment.

\section{References}

1. Shuenkin V.O. Theoretical foundations of logistics of troops (forces): textbook. way. / VO Shuenkin, IS Ishutin and others. - Kyiv: Central Research Institute of the Armed Forces of Ukraine, 2006. Part 1. 326 p. 2. Zakusylo P.S. Methods of substantiation of requirements to the system of complex repair of armored weapons and equipment of the army corps in the defense operation: dis. Cand. troops. Sciences: 20.01.05 "Construction of the Armed Forces" / PS Zakusilo. Kyiv, 2002. 175 p. 3. Pavlovsky O.V. Forecasting the amount of losses of weapons and military equipment during operations (combat operations). Weapons systems and military equipment, 2015, № 4 (44), p. 116-118. 4. Morozov, O.O. Methods for determining the volume of the exchange fund of units for the repair of weapons and military equipment. Military-technical collection, 2017, №16, p. 55-59. 5. Morozov, O.O. Methods of forming requirements for groups of current repairs of armaments and military equipment. Weapons systems and military equipment, 2016, № 1 (45) p. 51-55. 6. Shostak, V.G. To the task of determining the losses of motor vehicles of territorial troops. Bulletin of the Military Academy of the Republic of Belarus. 2013, №2 (39). - P.68-72. 7. V. Dachkovskyi Methodical approach to evaluation of economic efficiency of repairing the weapons and military equipment / V. Dachkovskyi, O. Sampir Y. Horbachova //

Journal of Scientific Papers VUZF review. - 2020. - Vol. 5, No 1, p. 22-30. DOI: https://doi.org/10.38188/25349228.20.1.03 8. Gavrilyuk, I.Yu. Matsko, O. Dachkovsky, V.O. Conceptual basis of flow management in the system of logistic support of the Armed Forces of Ukraine. Modern Information Technologies in the Sphere of Security and Defence - 2019. - № 1 (34) P. 37 - 44. DOI:10.33099/23117249/2019-34-1-37-44. 9. Dachkovskyi, V.O. The method of the optimization of material flows for functioning of the recovery system. Social development \& Security. - 2020. №10(2), $27-34$.

DOI: https://doi.org/10.33445/sds.2020.10.2.4

10. Dachkovskiy V.O. Radchenko, L.M. Recovery methodology weapons and military equipment Modern Information Technologies in the Sphere of Security and Defence. - 2019. - № 3 (36) p. 89-96. DOI:10.33099/23117249/2019-36-3-89-96 11. Dachkovskyi, V.O. Kotsyuruba, V.I. Method of evaluation of efficiency of functioning of arms and military engineering system. Modern Information Technologies in the Sphere of Security and Defence. - 2020. - № 1 (37) P. 5-14. DOI:10.33099/2311-7249/2020-37-1-514 12. Shuenkin V.O. Donchenko VS Applied models of the theory of queuing / Kiev: NMK VO "Educational and methodical office of higher education", 1992.398 with. 